\title{
Letters
}

Website: bmj.com

Email: letters@bmj.com

\section{Is the NHS guilty of ageism by not giving free personal care for some older people in England?}

EDITOR-Scotland's first minister has announced that he intends to implement free personal care in nursing homes for older people by April 2002. ${ }^{1}$ But the prime minister seems to believe that there are better things to spend money on in the English NHS. He overlooks the fact that the NHS Plan for England explicitly claims that it will eradicate ageism in the NHS.

Older people need personal care, not because they are old but because they have acquired disabling disease in old age. Thus the central tenets of the NHS would seem to be broken if older people do not receive the care they need, just because they are old. If this is a form of rationing then its criteria need to be made explicit. The current position that only care provided by registered nurses will be freely provided by the NHS is an inadequate basis on which to determine need and has all the hallmarks of covert rationing at the expense of a highly vulnerable sector of the community. It is also at odds with the national service framework for older people. ${ }^{2}$

The British Geriatrics Society believes that older people have the right to expect the best possible care from the NHS and

\section{Advice to authors}

We prefer to receive all responses electronically, sent directly to our website. Processing your letter will be delayed unless it arrives in an electronic form.

We are now posting all direct submissions to our website within 24 hours of receipt and our intention is to post all other electronic submissions there as well. All responses will be eligible for publication in the paper journal.

Responses should be under 400 words and relate to articles published in the preceding month. They should include $\leqslant 5$ references, in the Vancouver style, including one to the BMJ article to which they relate. We welcome illustrations.

Please supply each author's current appointment and full address, and a phone or fax number or email address for the corresponding author. We ask authors to declare any competing interest. Please send a stamped addressed envelope if you would like to know whether your letter has been accepted or rejected.

Letters will be edited and may be shortened.

bmj.com

letters@bmj.com

BMJ VOLUME 323 11 AUGUST 2001 bmj.com social services. Such care should include appropriate facilities and specialists to treat particular problems, not only acutely but also over the longer term.

Specialists in medicine of old age are key to reducing the costs of long term care:

- Firstly, through leading early and expert interdisciplinary assessment, diagnosis, and treatment to postpone and reduce the burden of need for long term care

- Secondly, by skilled and careful assessment of individual need and other alternatives before any decision is made to enter long term care

- And, finally, when long term care in homes is essential, by detailed evaluation of individual dependency as the basis for NHS funding-which may well include elements of personal as well as nursing and multidisciplinary care.

At present older people are given the impression of being seen more as a nuisance than as rightful consumers. Ageism in health care can be as insidious as racism. Perhaps, when some commentators complain about the problem of what to do about older people they should substitute the words "ethnic minorities" and see if the statement still appears reasonable.

I hope that the government in London will rapidly sort out its apparent internal inconsistency on this crucial issue as it introduces the national service framework.

Paul V Knight policy committee chairman British Geriatrics Society, London EC1M 4DN

1 Scottish Executive. The future for care homes in Scotland: a

2 Department of Health. National service framework for older people. London: DoH, 2001. (www.doh.gov.uk/nsf/

\section{New beginning for care for elderly people?}

National framework could transform care for older people in England

EDITOR-Grimley Evans and Tallis criticise the national service framework for older people. ${ }^{1}$ I agree with them that the policy to reduce emergency admissions to hospital only among the over $75 \mathrm{~s}$ is ageist. Application of the framework's age discrimination standard means that this high level performance measure will have to be changed to an age standardised measure. olderpeople.htm.
The framework model for intermediate care services requires there to be comprehensive assessment, active rehabilitation, and medical leadership involving both hospital specialists and general practitioners. There will be no return to 1960 s-style convalescence and other forms of marginalising older people.

On research strategy, the national framework supports the recommendations of the research and development strategic review to establish a national research advisory network for older people and for a directed programme of research; this has already commissioned a $£ 1.2 \mathrm{~m}$ programme to evaluate intermediate care.

On information provision, the framework will ensure scrutiny by patients and the public of all age based policies. It will also ensure the involvement of older people in patient forums, the local strategic partnerships, and the development of personal care plans that reflect individual needs, circumstances, and priorities.

The single assessment process will not replace medical diagnoses and decision making but will ensure that a single patient record is built up over time and shared among healthcare and social-care professionals, to replace the current inefficient and fragmented records systems.

Milestones for implementation of the falls standard are longer than those for some other parts of the framework as evidence is emerging about how best to organise this key component of services. Achieving organised services for the prevention and management of falls will be a great advance in the care of older people.

An inclusive approach was used throughout the development of the national service framework. The success of the approach is one reason why the framework has been so well received; it provides a historic opportunity for transforming health and social care for older people in England.

Ian Philp co-chair of executive reference group for national service framework

Department of Health, London SE1 8UG ian.philp@doh.gsi.gov.uk

$$
1 \text { Grimley Evans J, Tallis R. A new beginning for care for eld- }
$$
erly people? BMJ 2001;322:808-9. (7 April.)

\section{Proposals for intermediate care are} reinventing workhouse wards

EditoR-Grimley Evans and Tallis draw attention to the proposed development of intermediate care and its retrogressive nature. ${ }^{1}$ The rationale given for the implementation of intermediate care in the 
national service framework for older people is perplexing and inadequate. ${ }^{2}$

The framework states, firstly, that old people do not want to be in hospital. But if acute treatment is needed then hospital is often the best place to be. Secondly, it says that unplanned admissions might be avoided by prevention and rehabilitation. But intermediate care is not rehabilitation. Thirdly, it says that old people stay in hospital too long. This may well be true, but shunting sick people to another institution is not the solution.

The selective use of scientific evidence made by the framework to "support" intermediate care is remarkable. By its own admission "evaluative evidence of intermediate care schemes is scarce." Evidence for the benefits of hospital at home is cited as being a Cochrane/NHS Centre for Reviews and Dissemination systematic review but is not in either archive. Evidence on hospital at home is available in the Cochrane Library, ${ }^{3}$ but as the systematic review concludes that "there is insufficient evidence to assess the effects of hospital-at-home on patient outcomes or the cost to the health service" it was presumably deemed inadmissible.

A Cochrane review of the effects of intermediate nurse-led inpatient beds is planned (see Cochrane Library protocols) but has not yet been completed. A non-systematic review concluded, perhaps not surprisingly, that "methodological limitations render firm conclusions difficult."

The secretary of state for health decided that there should be intermediate care beds, and the national service framework had to come up with a post hoc justification for them. As with any new technology, it is sensible for it to be evaluated before being widely used in the NHS-that is what NHS research and development is for. In his rapid response on bmj.com (bmj.com/cgi/ eletters/322/7290/807\#EL3; above letter here in printed journal) Philp shows touching faith in intermediate care, asserting that it will be done properly. But in the absence of any decent evidence, how can he know how it should be done?

A return to the ethos of the workhouse wards (diagnostic failures, inadequate treatment and rehabilitation, long stays, complications), only recently removed from our NHS, seems quite probable but will clearly cost more than before. Acting as a mouthpiece for ministers seems to mean forfeiting scientific integrity-surely too high a price to pay.

Shah Ebrahim professor of epidemiology of ageing Department of Social Medicine, University of Bristol, Bristol BS8 2PR

shah.ebrahim@bristol.ac.uk

1 Grimley Evans J, Tallis R. A new beginning for care for elderly people? BMJ 2001;322:808-9. (7 April.)

2 Department of Health. National service framework for older people. London: DoH, 2001. (www.doh.gov.uk/nsf/ olderpeople.htm.

3 Shepperd S, Iliffe S. Hospital-at-home versus in-patien hospital care (Cochrane review). In: Cochrane Library. Issue 1. Oxford: Update Software, 2001

4 Griffiths P, Wilson-Barnett J. The effectiveness of "nursing beds": a review of the literature. I Advanced Nursing 1998;27:1184-92.
Problems with mental health are important too

EDITOR-It is unfortunate that Grimley Evans and Tallis concentrate only on the physical problems of old age. ${ }^{1}$ What of the "unworried unwell"-those with dementia? Years of socially oriented policy to deal with the problems of dementia may well have greatly improved the lot of carers. They have been of less help to patients themselves.

Few older people recognise the importance of late onset memory impairment. Even if they do they are unlikely to be referred to a specialist at an early stage in their illness, unlike those with other priority illnesses such as cancer, cardiovascular disease, and stroke.

Those who are fortunate enough to be referred see specialists hidebound in practice by health authorities continuing to resis the evidence base for treatment with cholinesterase inhibitors. ${ }^{2}$ People with dementia "shouldn't be" in acute medical wards, ${ }^{3}$ and bed blocking prevents admission to psychiatric inpatient care for assessment and to improve associated problems. Instead, they are channelled down the care slope through residential care, nursing home care, and nursing home care for elderly mentally infirm people.

In these environments care leaves a great deal to be desired. ${ }^{4}$ The policy of closing NHS beds has simply helped to fund the largest institutional care base in the country's history, ${ }^{5}$ yet a substantial proportion of people in institutions need not be there.

The national service framework, and similar work in Scotland, must provide an opportunity to improve the health care of people with dementia if these problems are to be addressed. Grimley Evans and Tallis are right to point out that no "in group" of civil servants should prevent this happening.

Peter Connelly consultant old age psychiatrist Murray Royal Hospital, Perth PH2 7BH peter.connelly@pk.tpct.scot.nhs.uk

1 Evans JG, Tallis RC. A new beginning for care for elderly people? BMJ 2001:322:807-8. (7 April.)

2 Allan K. Care for people with dementia in acute ward settings. Stirling: University of Stirling Dementia Services Development Centre, 2001.

3 National Institute for Clinical Excellence. Guidance on the use of donepezil, rivastigmine and galantamine for the treatment of Alzheimer's disease. London: NICE, 2001. (Technology appraisal guidance No 19.

4 Royal College of Physicians, Royal College of Nursing British Geriatric Society. The health and care of older people in care homes, a comprehensize disciplinary approach. London: RCP, 2000

5 Penrice GM, Simpson L, De Caestecker L, Brown G, Gillie S. Low dependency residents in private nursing homes in Glasgow. Health Bull 2001;59:15-9.

\section{Framework's recognition of importance} of stroke has substantial implications

EDITOR-The national service framework for older people, discussed by Grimley Evans and Tallis, ${ }^{1}$ recognises that stroke is a medical emergency and that patients will usually require urgent hospital admission. This will have substantial implications for the prehospital management of patients with acute stroke, which are not discussed in the document about the framework.

People who have had a stroke are more likely to survive and recover more function if admitted promptly to a hospital based stroke unit in an integrated stroke service. $^{2}$ Thrombolysis with intravenous alteplase is licensed for use within three hours of acute stroke in the United States and may receive licensing approval in Europe. Even within the first three hours the beneficial effects decline with increasing time to treatment. ${ }^{3}$

The median time from the onset of stroke to admission to hospital in the United Kingdom is 5.6 hours, ${ }^{4}$ which compares unfavourably with the 2.6 hours in the United States. ${ }^{5}$ Around $40 \%$ of patients with acute stroke in the United Kingdom make an emergency telephone call by dialling 999 (reaching hospital in a median of 2 hours); another $40 \%$ call their general practitioner (taking a median of 10 hours). ${ }^{4}$

Patients with acute stroke are mostly categorised by ambulance dispatchers in the United Kingdom as having a category B (non-life threatening) illness and are not transported to hospital with maximum haste. The failure to categorise stroke as a category A emergency, plus delays in accident and emergency departments before admission to an acute stroke unit, delay the delivery of skilled care and mean that most hospitals cannot participate in trials of treatments for acute stroke.

The widespread introduction of coronary care units and category A status for patients with suspected myocardial infarction provided the infrastructure that led to the evaluation and introduction of thrombolysis and revascularisation treatments. Similar investment by the NHS in acute stroke units and category A status for suspected acute stroke is necessary.

Paramedics need to be able to diagnose stroke rapidly and accurately and take patients quickly to hospitals with acute stroke units. Stroke recognition instruments have been validated in the United States for this purpose. In collaboration with the Northumbria Ambulance Service we have developed such an instrument (the face, arm, and speech test) for paramedics in the United Kingdom, which is presently undergoing validation.

The national service framework emphasises the urgency of acute stroke, but these recommendations will require substantial investment in public education, admission protocols, and the paramedical services to reduce unnecessary delays.

Damian Jenkinson consultant physician, stroke service Royal Bournemouth and Christchurch Hospitals NHS Trust, Royal Bournemouth Hospital, Bournemouth BH7 7DW damian.jenkinson@rbch-tr.swest.nhs.uk

Gary Ford professor of pharmacology of old age Freeman Hospital Stroke Service, University of Newcastle upon Tyne, Freeman Hospital, Newcastle upon Tyne NE7 7DN

1 Grimley Evans J, Tallis RC. A new beginning for care for elderly people? BMJ 2001;322:807-8. (7 April.)

2 Langhorne P, Dennis M. Stroke units: an evidence-based approach. London: BMJ Books, 1998.

3 Marler JR, Tilley BC, Lu M, Brott TG, Lyden PC, Grotta JC, et al for the NINDS rt-PA Stroke Study Group. Early stroke treatment associated with better outcome. Neurology 2000;55:1649-55. 
4 Gregson JM, Sharma A on behalf of the ASSIST Investigators. Does current practice in the immediate management of suspected acute ischaemic stroke or transient ischaemic attack provide for the criteria for thrombolysis with rt-PA? Cerebrovasc Dis 1999;9(suppl):99.

5 Morris DL, Rosamund W, Madden K, Schultz C, Hamilton S. Prehospital and emergency department delays after acute stroke. The Genentech stroke presentation survey. Stroke 2000;31:2585-90.

\section{Framework will have considerable effect} on primary care

EDITOR-Grimley Evans and Tallis's editorial talks about the effect that the national service framework for older people will have on hospital based care but does not mention the effect on primary care. ${ }^{2}$ Chapter 5 of the framework (on stroke) is largely concerned with the acute care and rehabilitation in secondary care of patients with a stroke or transient ischaemic attack. After only a passing mention of secondary prevention in the text, a key milestone is that by 2004 "every general practice can identify people who

No reference is made to the particular difficulties of identifying a cohort of patients who have previously had a stroke. Unlike with coronary heart disease, when patients are likely to have been prescribed a symptomatic treatment (for instance, a nitrate) in the past, it can be hard to identify patients who have had a stroke. ${ }^{3}$ This can lead to great inaccuracy in a practice's stroke register, as can be seen from our experiences.

We are based in an urban, relatively deprived area of Birmingham with a higher than average proportion of patients aged over $65(18 \%)$ and a list size of 5768. Our stroke register was previously maintained by opportunistic coding of consultations and summarising of hospital letters, a method used in many practices for their registers. ${ }^{4}$ We recently completed summarising and then computerising the medical histories of all of our patients and have noticed a large effect on our stroke register (table).

Before we reviewed our patients' notes 51 patients were recorded as having had a stroke or transient ischaemic attack. After the process 118 patients were so recorded. community surveys. ${ }^{5}$ Summarising and computerising required roughly 600 hours of doctor time, 500 hours of nurse time, and over 800 hours of administration time (nondoctors were paid for their time).

We believe that our original register was not dissimilar to registers in other practices. Stroke care was not the impetus behind our summarising effort, and it might be argued that concentrating on patients aged over 65 would have been more efficient. Nevertheless, as we assume that our experience is not unique many cases of have had a stroke." This final figure is similar to that found in

stroke will remain unidentified unless similar strategies are used elsewhere.

Until the problem of developing adequate stroke registers is tackled the management of most patients with stroke in primary care is likely to be unaffected by the national service framework for older people.

Richard J McManus general practitioner

r.j.mcmanus@bham.ac.uk

Louise Lumley general practitioner

Mandy Gough general practitioner

Lak Jhass general practitioner

Ken Deacon general practitioner

Greenridge Surgery, Birmingham B13 0PT

1 Evans JG, Tallis RC. A new beginning for care for elderly people? BMJ 2001:322:807-8. (7 April.)

2 Department of Health. National service framework for older people. London: DoH, 2001. (www.doh.gov.uk/nsf/ olderpeople.htm.

3 Gray J, Majeed A, Kerry S, Rowlands G. Identifying Gray J, Majeed A, Kerry S, Rowlands G. Identifying
patients with ischaemic heart disease in general practice patients with ischaemic heart disease in general practice:
cross sectional study of paper and computerised medical

records. BMJ 2000;321:548-50.

4 Moher M, Yudkin P, Turner R, Schofield T, Mant D. An assessment of morbidity registers for coronary heart disease in primary care. ASSIST (ASSessment of Implementation STrategy) trial collaborative group. $\mathrm{Br}$ Gen Pract 2000;50:706-9

5 O'Mahony PG, Thomson RG, Dobson R, Rodgers H, James OF. The prevalence of stroke and associated disability. J Public Health Med 1999;21:166-71.

\section{Authors' reply}

EDITOR-Although Philp agrees that a policy to reduce emergency admissions to hospital only among the over $75 \mathrm{~s}$ is ageist, he seems to think that this can be corrected by applying the national service framework's age discrimination standard, which will change a high level performance measure to an age standardised measure. This opaque formulation is the reverse of reassuring. Moreover, it will be interesting to know how either of these measures will be policed.

Equally unreassuring is Philp's assertion that there will be no return to 1960 s-style intermediate care as a mode of marginalising older people. It certainly does not deal with the concerns articulated by Ebrahim that intermediate care may represent "a return to the ethos of the workhouse wards (diagnostic failures, inadequate treatment and rehabilitation, long stays, complications)." Connolly's letter is especially relevant here; diversion of elderly psychiatric patients from acute facilities and a socially oriented approach to dementia has already been disastrous for the medical care of such patients.

If there is not to be a repeat of the 1960 s it will be essential to monitor closely how many older people "successfully" discharged from hospital into intermediate care, especially care purchased in the private sector, move sideways into permanent residence there rather than going back home. Can we rely on the necessary data being collected

Effect of summarising and computerising patient records. Figures are numbers (\%) of patients

\begin{tabular}{lccc} 
Category looked at & $\begin{array}{c}\text { Before notes were } \\
\text { reviewed }\end{array}$ & After notes were reviewed & List size \\
\hline All cases of stroke and TIA & $51(1)$ & $118(2)$ & 5768 \\
\hline Stroke and TIA in patients over 65 & $25(2)$ & $78(7)$ & 1045 \\
\hline
\end{tabular}

TIA=transient ischaemic attack. and made public? It is evident that the limited resources and even more limited person power available to deliver health care in the NHS will be spread even wider, and the creation of a new tier of service will be inefficient even if it does not result, as we anticipate, in serious inequities.

The emphasis on intermediate care was the result of the national service framework for older people being hijacked by the methodologically flawed national beds inquiry. The $£ 1.2 \mathrm{~m}$ programme to evaluate intermediate care looks pretty paltry compared with the huge sums earmarked for this evidence-free adventure dreamed up by policymakers remote from the real world and from the real challenges of providing technically up to date and humane care for desperately ill old people.

As for the single assessment process, Philp does little to assure us that this will not just become a bureaucratic nightmare, with many boxes being ticked and few people being helped. Besides, it is not clear what problem this single assessment process really will solve. (The most striking feature of the national service framework for older people is the lack of analysis of the reason why things have gone wrong hitherto.)

Jenkinson and Ford rightly emphasise the need for substantial investment in public education, admission protocols, and paramedical services in order to treat stroke with the urgency that it demands and deserves. Their own work in Northumbria is a model that could be adopted elsewhere. Such investment would be an interesting test of the rhetoric in the framework where there really is robust evidence to indicate the correct way forward.

McManus et al's point about the key role of primary care in implementation of the excellent stroke standard and of the resource implications that this has is entirely valid. Without the development of adequate stroke registers, secondary prevention and longer term follow up are going to remain as chaotic and inadequate as at present. Without the resources to support primary prevention measures in the primary care sector, the chances of achieving the targets of stroke reduction will be slender indeed.

It is too late now to change the national service framework for older people. The government should put its money where its rhetoric is and try to learn from some of the unexpected and uncomfortable experiences it is going to have with intermediate care so that the damage it causes may be limited; and civil servants should have less say in shaping the details of healthcare delivery. This framework could have a message for future national service frameworks: learning from experience is painful; learning from inexperience is even more painful as well as more expensive.

Raymond C Tallis professor of geriatric medicine University of Manchester, Manchester M13 9PL rtallis@fs1.ho.man.ac.uk

J Grimley Evans professor of clinical geratology University of Oxford, Oxford OX3 9DU 


\section{Maintaining older people's dignity and autonomy in healthcare settings}

\section{Whole system must be looked at to prevent degrading treatment}

EdITOR-Unfortunately, I cannot agree with Lothian and Philp in their article on the dignity and autonomy of older people in the healthcare setting. ${ }^{1}$ On several occasions I have put forward the view that British health care is failing older patients as a consequence of system-wide abuse of staff, managers, purchasers, and politicians..$^{23}$ As long as this corrosive, self sustaining culture remains untouched it is impossible to improve the dignity and autonomy of any group, let alone the more disadvantaged ones. What Lothian and Philp call the anecdotal evidence of a continuing, serious problem is already overwhelming and is still growing.

Recently, a 91 year old family member was finally given a hospital bed after being taken to an accident and emergency department after falling down the stairs. She had fractured three ribs and sustained a severe, immobilising calf injury. She spent eight hours, until $3 \mathrm{am}$, in hospital A's accident and emergency department on a trolley. She was admitted to a ward for six hours and then transferred to hospital $\mathrm{B}$, where she spent 10 hours in the accident and emergency department on a trolley, without food or drink until her daughter arrived, before being admitted to a ward.

After 18 hours she was transferred back to hospital A, where she waited again on a trolley in the accident and emergency department. Her daughter became distressed at this and made a formal complaint, whereupon a bed was found, although the atmosphere was unpleasant. At no point did she receive any considered investigation or treatment

Several dedicated, hard working, and kind NHS staff watched this happen with apparent indifference. If you can tell anything at all about theory from the current raft of documents from the Department of Health ${ }^{34}$ the government seems to explain this outrage (both what happened and what did not happen) in terms of either the absence of clear and agreed standards or, as Lothian and Philp do, inadequacies in training. The evidence for the former is overwhelmingly negative and for the latter at best scanty.

We must stop wasting time and energy on standards and frameworks ${ }^{5}$ : they simply add to the abusive cycle and make things worse. We must also stop the scapegoating of frontline staff by suggesting that retraining will help. Until we look at the whole system, away from the patients and staff immediately involved, we will never prevent such degrading treatment.

A J D Macdonald professor of old age psychiatry King's College London, Lewisham Hospital,

London SE13 6LH

alastair.macdonald@kcl.ac.uk
1 Lothian K, Philp I. Care of older people: Maintaining the dignity and autonomy of older people in the healthcare setting. BMJ 2001;322:667-70. (17 March.)

2 Macdonald A. The vicious circle of the system.J Dementi Care 2000;8:15-6.

3 Macdonald A. Where the buck stops. Guardian Society 2001 Jan 31:111.

Department of Health. The national plan. London: $\mathrm{DoH}$ 2000

Department of Health. National service framework for older people. London: $\mathrm{DoH}, 2001$.

\section{Elder abuse is both community and} healthcare issue

EdiTor-Lothian and Philp emphasised that the maintenance of an older person's dignity and autonomy is essential in a healthcare setting. ${ }^{1}$ They pointed out how this could be compromised by the insensitivity and disrespect of healthcare workers. But the negative comments of older service users and their carers that are quoted in the article seem to indicate more than just insensitivity. Some of them border on the deprivation of an older person's autonomy and dignity; this would be more appropriately termed elder abuse.

Roughly $3-5 \%$ of Australians aged over 65 suffer elder abuse, ${ }^{2}$ and these figures are similar to those in the United States. ${ }^{3}$ Only 1 in 14 cases is thought to be officially reported. ${ }^{4}$ The perpetrator is the victim's spouse in over half the reported cases and an adult son or daughter in a quarter. ${ }^{2}$ Elder abuse may be physical, psychological, or financial; neglect is also a form of abuse.

Few prevalence studies with carefully defined catchment populations are available in Australia. ${ }^{2}$ There is also a dearth of intervention studies for elder abuse. ${ }^{2}$ Few guidelines have been provided to healthcare workers with regard to the management and reporting of suspected abuse. These workers are required by law to attend child protection programmes, but no such educational schemes exist for the protection of elderly people. Because so little attention is devoted to elder abuse many cases go unreported.

Lothian and Philp proposed that a lack of education and training in hospitals predispose elderly people to this kind of abuse. ${ }^{1}$ They contended that "a key means of tackling poor attitudes by staff towards older people is through extensive and continued training." The healthcare setting has a vita role as a place of refuge for abused elderly people and gives healthcare workers an opportunity to identify abuse before it progresses. But focusing on abuse in these settings alone is too simplistic; elder abuse occurs elsewhere as well.

Wider community education is required as a primary preventive measure. Public awareness programmes outlining the prevalence and impact of elder abuse (similar to those used to prevent child abuse), as well as the promotion of geriatric services, would lead to a considerable improvement in both the notification and outcomes of abuse. Important geriatric services include respite care and family counselling. ${ }^{2}$

The value of Lothian and Philp's article is in its recognition that the dignity and autonomy of older people are being compromised. We must make the commu- nity and our healthcare workers aware that elder abuse is a problem.

Phillip Malouf student in community medicine, University of New South Wales

Felik Paulus student in community medicine,

University of New South Wale

Department of Ambulatory Care, Macarthur

Health Service, PO Box 149, Cambelltown 2560,

New South Wales, Australia

stephen.wilson@swsahs.nsw.gov.au

1 Lothian K, Philp I. Care of older people: Maintaining the dignity and autonomy of older people in the healthcare setting BMJ 2001·329.668-70.(17 March.)

2 Kurrle S, Sadler P, Cameron I Elder abuse-an Australian case series. Med Hust 1991;155:150-3.

3 Silveren J H Aus medical professionals. N C Med J 2000;61:291-6. Williams-Burgess C, Kimball MJ. The neglected elder: family systems approach.J Psychosoc Nurs Ment Health Ser

5 Bradley M. Caring for older people: Elder abuse. BMJ 1996;313:548-50

\section{Chemotherapy could be given at patients' workplace}

EDITOR-The first sentence of the editorial by Young and Kerr about home delivery of chemotherapy assumes that shifting care to the community means shifting it to patients' homes. ${ }^{1}$ This is echoed in the introduction of the paper by Borras et al about home versus hospital delivery of chemotherapy for people with colorectal cancer. ${ }^{2}$

In real life, however, many people are at work all day. For some of these, having treatment in the workplace would be more convenient than either home or hospital. I had a six month course of chemotherapy three years ago (although not for colorectal cancer), and usually I fitted in my chemotherapy around my work commitments. But having to go to the hospital for the treatment meant time out of the working day. If a nurse had come to my workplace there would have been much less disruption. As far as home treatment is concerned, that would have had little, if any, benefit for me because I would have had to wait in for the nurse to arrive (like waiting in for the plumber), or I would have had to go home during the working day to have the treatment. But having treatment at my workplace would have allowed me to get on with my work if there were delays in the nurse arriving, and it would have cut down on travelling.

People's individual circumstances and the state of their health will determine where it is best for them to have treatment, but in looking at alternative ways to deliver services, we need to think not just of home or hospital: people lead their lives in other places too, including places of work and study. Large places of work or study are likely to have a first aid or medical room and perhaps an occupational health nurse, so having treatment should be straightforward. Even in smaller places it is not necessarily impossible.

These principles apply not only to treatments for cancer but also for other diseases, particularly chronic diseases. In the past I have had weekly gold injections, which I had either at the hospital or at the general practitioner's surgery. The option of treat- 
ment in the workplace would have been very attractive, particularly as travelling, by any means, with active rheumatoid arthritis is rather a pain.

Joyce M Carter consultant in public health medicine Liverpool Health Authority, 24 Pall Mall, Liverpool, L3 6AL

joyce.carter@liverpool-ha.nhs.uk

Young AM, Kerr DJ. Home delivery: chemotherapy and pizza? BMJ 2001;322:809-10. (7 April.)

2 Borras JM, Sanchez-Hernandez A, Navarro M, Martinez M, Mendez E, Ponton JLL, et al. Compliance, satisfaction, and quality of life of patients with colorectal cancer receiving home chemotherapy or outpatient treatment: a randomised controlled trial. BMJ 2001;322:826. (7 April.)

\section{New approach to clinical trials and drug registration}

\section{Author's suggestions for drug approval are questionable}

EDITOR-Jones's proposal for a new approach to drug registration ${ }^{1}$ echoes industry views ${ }^{2}$ but hardly takes account of patients' interests, which are to have effective, safe, and cheap medicines. ${ }^{3}$ Experience indicates that phase I and II studies cannot replace phase III studies.

Advances in pharmacotherapy recently have been based on large randomised clinical trials in cardiovascular medicine, adopting a pragmatic approach with hard outcome measures. Much less has been achieved in oncology, where new substances have been tested in small, phase II, often uncontrolled studies, addressing surrogate or subjective end points. With a few hundred patients, as in phase I and II studies, assessing the true incidence of adverse reactions is impossible and establishing any meaningful ratio of benefit to risk is difficult.

Regulators must seek a balance between denying patients allegedly useful drugs and giving them immature products. Although their decisions mainly rely on randomised clinical trials, sometimes they grant conditional approvals to drugs for which it is still impossible to provide comprehensive information. ${ }^{4}$ This approach gives disappointing results: in its first five years the European Medicines Evaluation Agency granted 18 such approvals out of a total of 126. The conditional status has been revoked for only four products (three anti-HIV agents and a taxane).

For drugs whose approval is still conditional manufacturers were mostly committed to doing observational studies, which left questions unanswered. It is not considered feasible or ethical to do randomised clinical trials of the efficacy of products that have already been authorised, so, contrary to Jones's belief, obtaining postmarketing data on efficacy is difficult. Ineffective products cannot be withdrawn from the market, as this is envisaged only if there are "serious grounds for supposing ... a risk to human health."

What is truly unethical is to leave patients without sure answers-not without treatments of doubtful efficacy, which is what worries Jones. Patients must also be assured of the drugs' effectiveness and cost effectiveness. It is therefore mandatory to extend the aims of trials, which Jones complains about. Nobody except producers and wholesalers cares much about the efficacy of treatments that turn out to be unsuitable for most target patients.

These points cannot be addressed by theoretical models or animal and phase I and II studies, or left to surveys after approval; they call for adequately designed and adequately sized comparative trials to be done before marketing authorisation is granted.

Silvio Garattini director garattini@marionegri.it

Vittorio Bertele' head of regulatory policies laboratory "Mario Negri" Institute for Pharmacological Research, 20157 Milan, Italy

1 Jones TC. Call for a new approach to the process of clinical trials and drug registration. BMJ 2001;322:920-3. (14 April.)

2 European Federation of Pharmaceutical Industries and Associations (EFPIA). Evolution of standards. Available at: www.efpia.org.

3 Garattini S, Bertele' V. Policing the European pharmaceutical market's priorities. Eur $J$ Clin Pharmacol 2000:56:441-9.

4 Council Regulation (EEC) No 2309/93 of 22 July 1993 laying down community procedures for the authorization and supervision of medicinal products for human and vetand supervision of medicinal products for human and ve erinary use and establishing a European Agency for the Evaluation of Medicinal Products. Official Journal of the L 2141993 Aug 24:1.

5 Council Directive of 75/319/EEC of 20 May 1975 on the approximation of provisions laid down by law, regulation or administrative action relating to medicinal products. Official Journal of the European Communities No L 1471975 June 9:13.

\section{Author's reply}

EDITOR-The points raised by Garattini and Bertele' direct readers away from the major issues. My proposals are not an echo of industry views. Indeed, there has been little interest among pharmaceutical companies to make available all phase I and II clinical trial data, as I have recommended. Such companies have taken the view that this information must remain confidential and that, if it was made available, it would provide competitors with information they should not have. In addition, the requirement for complex phase III trials tends to favour large pharmaceutical companies against smaller ones and generic competitors.

Two critical steps need to be taken: phase I and II trials must be done following presently articulated standards of the best clinical trials, and all data from these trials must be available for review. A third step, as I indicated in my article, is that a thorough study of the adverse event profile at the end of phase II be compared with that at the end of phase III.

Garattini and Bertele' state that "experience indicates that phase I and II studies cannot replace phase III studies." This is our major disagreement. Their experience differs from mine, and the data to resolve our different views are in the archives of pharmaceutical companies and regulatory offices. These data should be brought into the medical literature, where they can be critically analysed. The data comparing cardiovascular drugs with oncology drugs do not help solve this issue, nor does the approval process for conditional status.

The authors raise an important point that I did not address in my article. European guidelines for withdrawing a drug from the market on the basis of postmarketing surveillance data are at present insufficient. The argument that this means that the system must be maintained is misplacedthe guidelines must be tightened.

I strongly disagree with the view that my proposals do not take into account patients' interest to have effective, safe, and cheap medicines. It is the excessive time and cost of phase III clinical trials, plus minimum new information about either drug efficacy or safety resulting from phase III, that is largely responsible for the lack of availability of medicines to patients. It is this problem that has led to my proposal for a new approach.

Thomas $\mathbf{C}$ Jones adjunct professor of medicine

Cornell University

Clinical Research Consultants, Basle 4058 Switzerland

100767.711@compuserve.com

\section{Surgeons' attitudes to intraoperative death}

\section{Cardiac surgeons might have different attitudes}

EDITOR-Smith and Jones found out the attitudes of several surgeons to the edict from Sheriff Albert Sheenan in Scotland. ${ }^{1}$ I suspect, however, that if the same questionnaire had been sent to cardiac surgeons, the response might have been different.

There are essential differences in the significance of intraoperative deaths between cardiac and non-cardiac surgery. In cardiac operations the patients are being kept alive by the heart-lung machine while the surgeon operates on the heart, and it is only at the end of the procedure that an attempt is made to persuade the patient's heart to take over the circulation. After gastric surgery, the patient is not expected to eat a large meal immediately after. Similarly, after lower limb surgery the patient is not expected to jump off the operating table and run back to his bed. In cardiac surgery, however, it is essential that the heart resumes its work immediately at the end of the procedure. Intraoperative deaths occur usually when the heart is unable to do so successfully despite maximal pharmacological and sometimes mechanical support.

Intraoperative deaths therefore suggest that the operation has not been done in a technically perfect way, that the ischaemic period of the heart was too long, or that the heart was not protected adequately during the ischaemic period. All these are the responsibility of the surgeon and not the anaesthetist. It is therefore the surgeon on whom the burden of an intraoperative death tends to fall. Intraoperative deaths in cardiac surgery occur only after the surgeon has tried again and again to wean the patient off the heart-lung machine. This tends to take many hours. These operations are therefore 
both physically and psychologically draining, and most cardiac surgeons would probably find the advice of the sheriff both appropriate and comforting.

Norman Briffa consultant cardiothoracic surgeon University Hospital Coventry and Warwickshire NHS Trust, Coventry CV2 2DX

Norman.Briffa@btinternet.com

1 Smith IC, Jones MW. Surgeon's attitudes in intraoperative death: questionnaire survey BMJ 2001;322:896-7. (14 April.)

Anaesthetic departments need action plans to deal with such catastrophes

EDITOR-Smith and Jones surveyed surgeons' attitudes to intraoperative death. ${ }^{1}$ This subject affects anaesthetists equally, if not more, as they are closely manage the patient's wellbeing during surgery. In this, as in a previous article, Jones does not take into consideration the effects that an unexpected intraoperative death has on other members of the medical and nursing staff, and the relatives concerned. ${ }^{2}$

Few articles address this subject in anaesthesia. Anaesthesia training centres focus almost exclusively on preventing potential disasters, whereas nothing really prepares anaesthetists in how to deal with them when they occur. ${ }^{3}$ Anaesthesia related deaths are extremely rare, but they do happen, often unexpectedly, leaving the individual anaesthetist feeling devastated. The emotional effects on anaesthetists are seldom discussed, and debriefing after a death is often haphazard. Guidelines on how to handle such a situation are available in only very few anaesthetic departments. We all assume that this will happen to somebody else, rather than ourselves, leaving the anaesthetist to whom it happens often feeling isolated and with little support. ${ }^{4}$ The nursing staff is likely to be equally affected, especially if children or young otherwise healthy adults are involved. There is a clear need to include the management of anaesthesia disasters into the curriculum of anaesthesia training.

Anaesthetic departments should have action plans on how to deal with catastrophes to reduce the suffering for all those involved. These should include guidelines on breaking the news to the family, the format of the interview, hospital paperwork, preparation for possible civil proceedings, and the debriefing of the theatre team. ${ }^{4}$ In an environment of clinical governance and an increasingly litigious society the question remains if the remainder of the operating list should be continued by a completely new team, including surgeon and nursing staff. On a background of suicide rates among anaesthetists, which are 10 times higher than those of the average population, it is important that we all support each other and help new generations of anaesthetists with guidance and open discussion.

Boerge Christoph Seifert visiting instructor in anaesthesiology

University of Michigan, Ann Arbor, MI 48105, USA cseifert@med.umich.edu

1 Smith IC, Jones MW. Surgeon's attitudes in intraoperative death: questionnaire survey. BMJ 2001:322:896-7. (14 April.)
2 Jones M. Death on the operating table. BMJ 2000;320:881.(25 March)

3 Aitkenhead AR. Anaesthetic disasters: handling the aftermath. Anaesthesia 1997;52:477-82.

4 Bacon AK. Death on the table. Anaesthesia 1989;44:245-8.

\section{$H$ pylori testing and endoscopy for dyspepsia in primary care}

\section{Improved diagnostic accuracy is important in dyspepsia}

EDITOR-Delaney et al's trial of Helicobacter pylori testing and endoscopy for dyspepsia in primary care surely misses the point of medical consultations for dyspepsia. ${ }^{1}$ Most doctors would view the purpose of a consultation as primarily to make a diagnosis before starting treatment. If the purpose is to initiate empirical prescribing-these authors seem to advocate this as they conclude that this "is ... the best treatment"- the patients might as well go to a pharmacist and treat themselves.

This study is flawed. It uses a screening test for $H$ pylori (Helisal) that has been reported to have sensitivities of only $67-88 \%$, with a specificity of $78-91 \% .^{23}$ The test is therefore not an accurate means of detecting $H$ pylori, which presumably explains why so many ulcers were found in the control patients who were $H$ pylori negative (four out of 48 endoscopies carried out).

Conclusions have been drawn on symptomatic follow up and quality of life data that were recorded for only just over half the patients studied. Costs were greater in patients in the study group, who all had endoscopy. We are not told whether these costs were significantly higher, but certainly some of this was due to the cost of $H$ pylori testing, which, for some reason, was significantly higher $(\mathrm{P}<0.0001)$ in the study group.

As the authors acknowledge, endoscopic investigation showed significantly more peptic ulcers than did standard management. Presumably the patients themselves would be interested in knowing this, since subsequent successful $H$ pylori eradication treatment should produce cure of their ulcers rather than them having to continue with empirical acid suppressant treatment long term. The National Institute for Clinical Excellence has produced guidance on the use of proton pump inhibitors in the treatment of dyspepsia. It concluded that patients with non-ulcer dyspepsia-whom Delaney et al accept make up most of their patients-"may have symptoms caused by different aetiologies and should not be routinely treated with [proton pump inhibitors]."

Time has left these authors behind. Colleagues and I have shown that adding serum recognition of the CagA protein and serum pepsinogen I levels to simple but reliable $H$ pylori serology further refines diagnostic accuracy and could reduce the endoscopy workload for patients with dyspepsia by about half. ${ }^{5}$ What patients with dyspepsia need is improved diagnostic accuracy and specifically tailored treatment, not further encouragement to take empirical treatment for life without any clear idea of why, apart from amelioration of symptoms.

Val Heatley consultant gastroenterologist St James's University Hospital, Leeds LS9 7TF e.m.tasker@leeds.ac.uk

1 Delaney BC, Wilson S, Roalfe A, Roberts L, Redman V, Wearn A, et al. Randomised controlled trial of Helicobacter pylori testing and endoscopy for dyspepsia in primary care. BMJ 2001;322:898-901. (14 April.)

2 Duggan A, Logan R, Knifton A, Logan R. Accuracy of near-patient blood tests for Helicobacter pylori. Lancet 1996;348:617

3 Moayyedi P, Carter AM, Catto A, Heppell RM, Grant PF, Axon ATR. Validation of a rapid whole blood test for diagnosing Helicobacter pylori infection. BMJ 1997;314:119.

4 National Institute for Clinical Excellence. guidance on the use of proton pump inhibitors in the treatment of dyspepsia. London: NICE, 2000.

5 Bodger K, Wyatt JI, Heatley RV. Serologic screening before endosocpy: the value of Helicobacter pylori serology serum recognition of the $\mathrm{Cat} A$ and $\mathrm{V}$ pylori serology PacA proteins, and

\section{Authors' reply}

EDITOR-Initial empirical treatment for symptomatic presentations when the risk of serious disease is low remains an essential component of gatekeeping in primary care. Without such pragmatic problem solving, the proportion of the NHS expenditure that is consumed by primary care would rise considerably above the current $6.5 \%$

Time has indeed moved on, and randomised controlled trials take longer to perform than it takes to write guidelines without appropriate evidence. Reliable data fortunately support common sense in suggesting that we do not yet need to explore the consequences of such diagnostic reductionism.

The comparator in this study was not empirical prescribing forever, as Heatley suggests, but general practitioners' usual care, consisting of empirical prescribing, referral, and follow up as judged appropriate. In fact, $25 \%$ of the control group had an endoscopy during the year of follow up. Given that symptom patterns and tests for Helicobacter pylori do not predict diagnosis, ${ }^{1}$ initial empirical prescribing is appropriate for many patients. ${ }^{2}$

The Helisal test was locally validated, with a sensitivity of $89 \%$ and a specificity of $84 \%$. More accurate tests would reduce the false positive rate, but even if the $H$ pylori status was known with $100 \%$ accuracy more than half of the additional referrals for endoscopy would still have been made.

Although only $61 \%$ of patients returned symptom and quality of life questionnaires, we had resource use data on $99 \%$, and the result was stable to adjustment for differences in baseline characteristics of non-responders. Costs were significantly higher in the study group ( $\mathrm{P}=0.0044)$, due mainly to the cost of the additional $20 \%$ of patients who had endoscopy, as the cost of endoscopy is $£ 246$ compared with $£ 12$ for an $H$ pylori test.

Healthcare expenditure is to a large extent determined by the decisions made by individual clinicians. Some treatments produce more health gain than others, and some entail more parsimonious use of resources. Although we did detect more peptic ulcers, it is symptom resolution that matters. As non-ulcer dyspepsia responds to $H$ pylori eradication with symptom resolution in 
1 in 15 patients treated," "test and eradicate" has been proposed as a cost effective management strategy. We have recently received funding to conduct the CUBE trial, a randomised controlled trial of test and eradicate using a breath test versus four weeks' treatment with a proton pump inhibitor for the initial management of dyspepsia.

Brendan C Delaney senior lecturer

b.c.delaney@bham.ac.uk

Sue Wilson senior research fellow

Andrea Roalfe medical statistician

Lesley Roberts research fellow

Andrew Wearn lecturer

F D Richard Hobbs professor of primary care and general practice

Department of Primary Care and General Practice, University of Birmingham Medical School, Birmingham B15 2TT

1 Hansen JM, Bytzer P, deMuckadell OBS. Management of dyspeptic patients in primary care: value of the unaided clinical diagnosis and of dyspepsia subgrouping. Scand Gastroenterol 1998:33:799-805.

2 National Institute for Clinical Excellence. Guidance on the use of proton pump inhibitors in the treatment of dyspepsia. London: NICE, 2000. (www.nice.org.uk/nice-web/pdf/ proton.pdf; accessed 19 March 2001.)

3 Moayyedi P, Soo S, Deeks J. Innes MA, Forman D, Delaney BC. Aed P, Soo S, Deeks J, Innes MA, Forman D, Delaney BC. A syst Soo S, Decks effectives of dyspepsia (NUD). BMJ 2000;321:659-64.

\section{Test and treat seems best}

EDITOR-Delaney at al have shown that near patient testing for Helicobacter pylori, followed by open access endoscopy for patients in whom results are positive, increases demand for endoscopy and is not cost effective. ${ }^{1}$ By contrast, trials of test and treat strategies without endoscopy in young patients indicate that this policy may be cost effective in the clinical setting..$^{2-4} \mathrm{~A}$ recent survey of practice in my own department tends to support this proposition.

In 1997, as part of locally based dyspepsia management guidelines, a test and treat policy for patients under 45 with dyspepsia and without alarm symptoms was introduced in the community referring patients to the open access endoscopy service at Queen Mary's Hospital, Sidcup. Only those young patients who continued to have dyspepsia after treatment appropriate to their H pylori status and predominant symptoms were accepted for endoscopy.

Open access referrals from the community before and after the guidelines were introduced were compared. In the three years after the test and treat policy was introduced there was a $4.3 \%$ decrease (from a mean of 163 to 156 per year) in the referral of young patients but a $21 \%$ increase (from a mean of 466 to 564 per year) in the referral of those aged over 45. Had the referral rate in young patients kept pace with that in older patients it would have increased the open access waiting list by a further nine weeks over this three years.

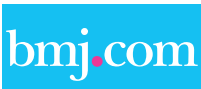

\section{Rapid responses}

Correspondence submitted electronically is available on our website
The policy seems not to have devalued the procedure in this group of patients. Altogether $54 \%$ of young patients with dyspepsia $(88 / 163)$ had a normal endoscopy before the test and treat policy was introduced, compared with 42\% (65/156) after the policy was introduced; the reduction was almost entirely due to an increase in the diagnosis of oesophagitis.

This survey therefore suggests that, in contrast to "test and endoscope," test and treat when applied in routine primary care can reduce demand for endoscopy and may be more cost effective than early endoscopy based strategies.

M J Lancaster Smith consultant gastroenterologist Queen Mary's Hospital, Sidcup, Kent DA14 6LT Kerry.sharpe@qms-tr.sthames.nhs.uk

Delaney BC, Wilson S, Roalfe A, Roberts L, Redman Wearn A, et al. Randomised controlled trial of Helicobacter pylori testing and endoscopy for dyspepsia in
primary care. BMJ 2001;322:898-901. (14 April.) primary care. BMJ 2001,322.898-901. (14 Apri ord KB, Tham TCK. A prospective randomised trial of "test and treat" policy versus endoscopy based management in young Helicobacter pylori positive patients with ulcer-like dyspepsia referred to a hospital clinic. Gu 1999;45:186-90.

3 Jones R, Tait C, Sladen G, Weston-Baker J. A trial of a test and treat clarity strategy for Helicobacter pylori positive dyspeptic patients in general practice. Int J Clin Prac 1999;53:413-6.

4 Lassen AT, Pedersen FM, Bytzer P, Schaffalitzky de Muckadell OB. Helicobacter pylori test-and-eradicate versus prompt endoscopy for management of dyspeptic patients: a randomised trial. Lancet 2000;356:455-60.

\section{Some patients seem not to have been included in census}

EDITOR-Target payments to health authorities and primary care trusts are based on the number of people recorded as living in the area in the national census. Discrepancies between this figure and the number recorded as being on general practitioners' lists puts pressure on health authorities to have patients removed from lists if the authorities believe that they no longer live at the address at which they are registered.

Our practice serves a population that includes some $60 \%$ people of Asian or African origin. A considerable proportion are not fluent in English; some have arrived in Britain within the past three years, and we have about the expected number of people with dementia or psychosis. We suspected that these factors might limit their ability or willingness to take part in the census.

Over three weeks we asked consecutive or nearly consecutive patients seen at our surgery or the adults who accompanied them whether they were included in the census. We have recorded the findings. We also recorded fean

whether these patients had come to Britain in the past three years, whether they were fluent in English, and whether they had an appreciable mental health problem. The table shows our findings.

Although patients attending our practice may not be representative of the population as a whole, $23 \%$ of those asked either stated that they were not included in the census or did not know whether they were. We conclude that the census greatly underestimates the number of people resident in an area such as ours, to the detriment of funding of local NHS services.

We found that people underrepresented in the census were particularly those recently arrived in Britain, those least fluent in English, and those with mental health problems. These are some of the people who can most benefit from services in general practice. We have an impression that living in multioccupancy accommodation such as "bedsits" also leads to underrepresentation in the census, but we did not include this factor in the survey.

Alick J Munro general practitioner

Mark Chambers general practitioner

Anthony Marwaha general practitioner

Cranford Medical Centre, Cranford, Middlesex

TW5 9RG

\section{Sudden death may not be best}

EDITOR-While probably no one would want to argue for the desirability of a slow, painful death, I do not think that everyone would want to agree with Indrayan's belief that a sudden death is the best way to die. ${ }^{1}$ I certainly do not.

In medieval times a good death was a prepared death. Books were published on the art of dying and generally it was believed that a sudden, unprepared death was something horrible, maybe even a sign of being damned. A sudden death would not allow for confession of sins, last rites, last goodbyes, sorting of one's affairs, etc. In some ways more recent publications like Kübler-Ross's books could be seen of promoting a similar view-progressing through the stages of dealing with one's diagnosis and prognosis one can develop something like a new peace and even joy in the face of death.

Isn't the modern wish for a sudden, unexpected death just another aspect of the general denial of our mortality?

Peter von Kaehne general practitioner Fernbank Medical Centre, Glasgow G22 6BD vkaehne@doctors.org.uk

1 Indrayan A. Can I choose the cause of my death? BMI 2001;322:1003. (21 April.)

Patients seen over three weeks who were or were not included in census

\begin{tabular}{llll} 
& Included in census (A) & Not included in census (B) & Significance \\
\hline Total & 151 & 44 & \\
\hline Came to United Kingdom in past 3 years & 34 & 26 & $\mathrm{P}<0.001^{*}$ \\
\hline Fluent in English & 121 & 16 & $\mathrm{P}<0.001^{*}$ \\
\hline Mental health problem & 6 & 7 & $\mathrm{P}<0.01 \dagger$ \\
\hline Male & 57 & 20 & $\mathrm{NS}$ \\
\hline Mean (SD) age (years) & $47.1(21.5)$ & $40.9(23.3)$ & $\mathrm{NS}$ \\
\hline
\end{tabular}

$A /(A+B)=77 \%$. ${ }^{*} Z_{c}$ test for proportion. + Fisher's exact test. 